\title{
BRONCHIAL ARTERY EMBOLISATION IN MASSIVE HAEMOPTYSIS
}

\author{
Siddharth Prakash ${ }^{1}$, Kavita Saggar2, Vikram Narang ${ }^{3}$
}

${ }^{1}$ Assistant Professor, Department of Radiodiagnosis, Dayanand Medical College and Hospital, Ludhiana, Punjab. 2 Professor and HOD, Department of Radiodiagnosis, Dayanand Medical College and Hospital, Ludhiana, Punjab. ${ }^{3}$ Assistant Professor, Department of Pathology, Dayanand Medical College and Hospital, Ludhiana, Punjab.

\section{ABSTRACT}

\section{BACKGROUND}

Bronchial artery embolisation is a minimally invasive procedure in life-threatening massive haemoptysis due to markedly hypertrophied and fragile bronchial arteries occurring in patients with chronic inflammatory lung diseases such as bronchiectasis, sarcoidosis, tuberculosis, or cystic fibrosis.

\section{MATERIALS AND METHODS}

This case series analysis was conducted in the Department of Radiodiagnosis, Dayanand Medical College and Hospital, Ludhiana, Punjab over a period of three and half years (June 2013 - December 2016). The adult patients (>18 years of age) with massive haemoptysis, managed by embolising branches of bronchial artery were included.

\section{RESULTS}

Of the total 35 patients in which BAE was attempted, immediate control of haemoptysis was seen in 32 (91.4\%). On followup, recurrent haemoptysis was seen in 6/30 (20\%) patients with major cause of recurrence being fibrocystic changes in $3 / 6(50 \%)$.

\section{CONCLUSION}

$\mathrm{BAE}$ is a safe noninvasive procedure to tackle massive haemoptysis in patients where surgical interventions are contraindicated.

\section{KEYWORDS}

Haemoptysis, Bronchial Artery, Embolisation, Intervention, Radiology.

HOW TO CITE THIS ARTICLE: Prakash S, Saggar K, Narang V. Bronchial artery embolisation in massive haemoptysis. J. Evolution Med. Dent. Sci. 2017;6(47):3624-3628, DOI: 10.14260/Jemds/2017/781

\section{BACKGROUND}

Massive haemoptysis, a frightening and potentially lifethreatening clinical event, due to markedly hypertrophied and fragile bronchial arteries is common in patients with chronic inflammatory lung diseases such as bronchiectasis, sarcoidosis, tuberculosis, and cystic fibrosis. Surgical interventions like local resections may be curative in focal lesions but are hazardous and also often impossible in patients with diffuse parenchymal lung disease. ${ }^{1-3}$

Bronchial artery embolisation offers a minimally invasive procedure, is a treatment of choice in such patients. Even the most compromised patients serving can also be successfully managed with bronchial artery embolisation as first-line treatment for haemorrhage as well as providing a bridge to more definitive medical or non-emergent surgical intervention focused upon the aetiology of the haemorrhage. ${ }^{4-5}$ Though the bronchial artery embolisation is a well-known procedure the data regarding its efficacy is scarce, thus the study was planned to analyse the outcome of patients undergoing BAE for massive haemoptysis in our institute.

Financial or Other, Competing Interest: None.

Submission 30-04-2017, Peer Review 31-05-2017,

Acceptance 05-06-2017, Published 12-06-2017.

Corresponding Author:

Siddharth Prakash,

Assistant Professor,

Department of Radiodiagnosis,

Dayanand Medical College and Hospital,

Ludhiana.

E-mail: siddprak@gmail.com, drvikramnarang@yahoo.com

DOI: $10.14260 /$ jemds $/ 2017 / 781$

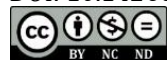

\section{MATERIALS AND METHODS}

This case series analysis was conducted in the Department of Radiodiagnosis, Dayanand Medical College and Hospital, Ludhiana, Punjab over a period of three and half years (June 2013-December 2016). The adult patients ( $>18$ years of age) with massive haemoptysis, managed by embolising branches of bronchial artery were included. The demographic profile, aetiology of massive haemoptysis, duration of underlying disease and post-procedure followup was recorded as per predesigned proforma.

Massive haemoptysis was defined as expectoration of at least $200 \mathrm{~mL}$ of blood per hour in a patient with normal or nearly normal lung function, production of at least $50 \mathrm{~mL}$ of blood per hour in a patient with a chronic respiratory failure, or more than two episodes of moderate haemoptysis (at least $30 \mathrm{~mL}$ ) within a 24-hour period despite the use of IV vasopressin.

Chest radiographs were done for all patients and radiological abnormalities were identified. Bronchial arteriograms were always performed before attempting embolisation and any abnormalities in the artery course/variations in anatomy and reasons for haemoptysis were recorded.

\section{Procedure}

The procedure was carried out in the supine position using a transfemoral Seldinger technique under local anaesthesia. The number of embolised vessels per procedure ranged from 1 to 5 . Either $4 \mathrm{~F}$ or $5 \mathrm{~F}$ curved Cobra or Judkin's Right catheters were utilised for catheterisation of the bronchial arteries. Search for the bronchial artery opening was made at D4 to D6 Levels and if necessary it was extended to the 
intercostal, diaphragmatic and internal and lateral thoracic arteries. Arteries were considered pathologic if they were hypertrophied, or demonstrated vascular blush or arteriovenous shunting. Extravasation of the contrast agent was not visualised in any patient. Embolisation was performed using 355 to $500 \mathrm{u}$ (Boston Scientific) polyvinyl alcohol particles followed by a slurry of Gelfoam. Diagnostic angiography was routinely performed during the embolotherapy procedure to exclude the presence of spinal arteries arising from the bronchial or intercostal arteries. Spinal arteries, if found were not considered a contraindication to embolisation. A coaxial microcatheter system (Progreat, Terumo) was used to bypass the origin of possible spinal artery. The vessels embolised included right $29(82.5 \%)$ and left 25 (71.4\%) Intercostal bronchial trunk, common bronchial trunks $3 / 35$ (8.6\%), intercostal arteries $13 / 35$ (37.1\%), and internal mammary arteries $3 / 35$ (8.6\%) and lateral thoracic in $4 / 35$ (11.4\%) patients. Polyvinyl alcohol followed by Gelfoam sponge was used in most patients (97\%) to cut down on cost accrued on particles. Only one patient received an additional coil for embolisation.

\section{RESULTS}

A total of 35 patients (mean age 48.3 years; $\mathrm{M}: \mathrm{F}=2.9: 1$ ) were included in the analysis. Acute infective pathology $(12 / 35$, $34.2 \%$ ) was the commonest cause for haemoptysis followed by active tuberculosis $(11 / 35,31.4 \%)$, tuberculosis sequelae $(10 / 35,28.5 \%)$, pulmonary aspergilloma $(2 / 35,5.7 \%)$. The radiological abnormalities on X-ray were seen as consolidation in 20 (57.1\%), cavitatory changes in 15 (42.9\%), fibro-cystic changes in 11 (31.4\%), segmental/subsegmental collapse in $4(11.4 \%)$ and pleural effusion in two (5.7\%). Bronchial arteriograms performed before attempting embolisation showed bronchial artery hypertrophy 28 (80\%), and shunting in 7 (20\%) and pseudoaneurysm in 2 patients. (Fig. 1).

Of the total 35 patients in which BAE was attempted, immediate control of haemoptysis was seen in 32 (91.4\%). Of the 3 patients who failed to respond, two were treated with alternative approaches which included repeat embolisation, lobectomy; however, the third patient died. The two patients expired in immediate post-op period, due to cardiac arrest $(1 / 2)$ and massive bleed (1/2). On followup, recurrent haemoptysis was seen in $6 / 30(20 \%)$ patients with major cause of recurrence being fibrocystic changes in $3 / 6(50 \%)$ or consolidation in 2 and combination of above in 1 patient. (Table 1).

\begin{tabular}{|c|c|c|}
\hline \multicolumn{2}{|c|}{ Characteristics } & N (\%Age) \\
\hline \multirow{2}{*}{ Age } & $<40$ years & $10(28.5 \%)$ \\
\cline { 2 - 3 } & $>40$ years & $25(71.4 \%)$ \\
\hline \multirow{3}{*}{ Gender } & Male & $26(74.2 \%)$ \\
\cline { 2 - 3 } & Female & $09(25.7 \%)$ \\
\hline \multirow{3}{*}{ Hetiology } & Active tuberculosis & $11(31.4 \%)$ \\
\cline { 2 - 3 } & Tuberculosis sequelae & $10(28.5 \%)$ \\
\cline { 2 - 3 } & Acute Infective aetiology & $12(34.2 \%)$ \\
\cline { 2 - 3 } & Pulmonary aspergilloma & $02(5.7 \%)$ \\
\hline \multirow{2}{*}{$\begin{array}{c}\text { X-ray/ } \\
\text { CT findings }\end{array}$} & $\begin{array}{c}\text { Chronic recurrent } \\
\text { haemoptysis }\end{array}$ & $33(94.2 \%)$ \\
\cline { 2 - 3 } & Consolidation & $02(5.7 \%)$ \\
\cline { 2 - 3 } & Cavitation & $20(57.1 \%)$ \\
\cline { 2 - 3 } & Fibrocystic changes & $11(31.4 \%)$ \\
\cline { 2 - 3 } & Pleural effusion & $2(5.7 \%)$ \\
\hline
\end{tabular}

\begin{tabular}{|c|c|c|}
\hline & Collapse & $4(11.4 \%)$ \\
\hline \multirow{4}{*}{$\begin{array}{l}\text { Bronchial } \\
\text { arteriogram } \\
\text { findings }\end{array}$} & $\begin{array}{l}\text { Bronchial artery } \\
\text { hypertrophy }\end{array}$ & $28(80 \%)$ \\
\hline & Hypervascularity & $24(68 \%)$ \\
\hline & Shunting & $07(20 \%)$ \\
\hline & Pseudoaneurysm & $02(5.7 \%)$ \\
\hline \multirow{6}{*}{$\begin{array}{l}\text { Vessels } \\
\text { embolised }\end{array}$} & Rt ICBT & $29(82.9 \%)$ \\
\hline & Lt ICBT & $25(71.4 \%)$ \\
\hline & Bronchial trunks & $03(8.6 \%)$ \\
\hline & Intercostal arteries & $13(37.1 \%)$ \\
\hline & Lateral thoracic & $04(11.4 \%)$ \\
\hline & $\begin{array}{l}\text { Internal mammary } \\
\text { arteries }\end{array}$ & $03(8.6 \%)$ \\
\hline \multirow{4}{*}{$\begin{array}{l}\text { Post-procedure } \\
\text { complications }\end{array}$} & Chest pain & $07(20 \%)$ \\
\hline & $\begin{array}{l}\text { Transient Dissection } \\
\text { (bronchial and } \\
\text { intercostals) }\end{array}$ & $02(5.7 \%)$ \\
\hline & $\begin{array}{l}\text { Bronchial tree } \\
\text { embolisation }\end{array}$ & $01(2.8 \%)$ \\
\hline & Monoparesis & $01(2.8 \%)$ \\
\hline \multirow{3}{*}{ Followup } & Immediate Recurrence & $3 / 33$ \\
\hline & Recurrence within 30 days & $\begin{array}{c}1 \text { (single } \\
\text { episode)/33 }\end{array}$ \\
\hline & Recurrence $>30$ days & $6 / 30$ \\
\hline \multicolumn{3}{|c|}{ Table 1. Baseline Characteristics of Patients $(n=35)$} \\
\hline
\end{tabular}
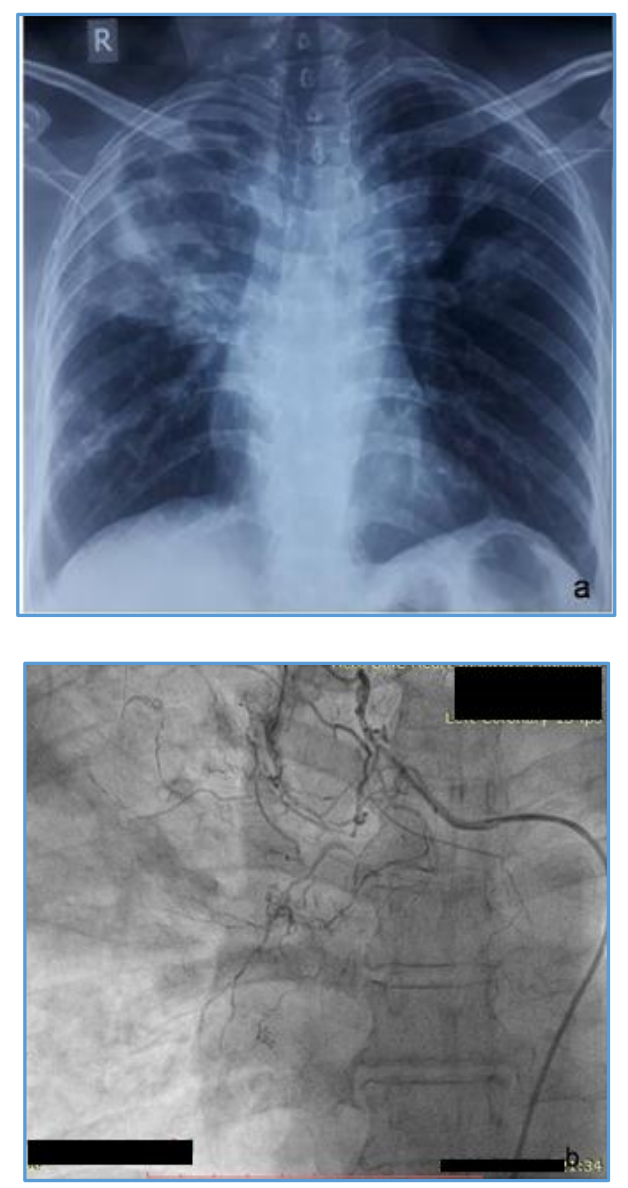

Figure 1. (a) X-ray chest shows collapse consolidation with areas of breakdown in right upper lobe, patchy consolidation also visualised in right lower lobe and left upper lobe. (b) Bronchial angiogram shows

hypertrophied, torturous right intercostal bronchial trunk with parenchymal blush in right upper lobe. 

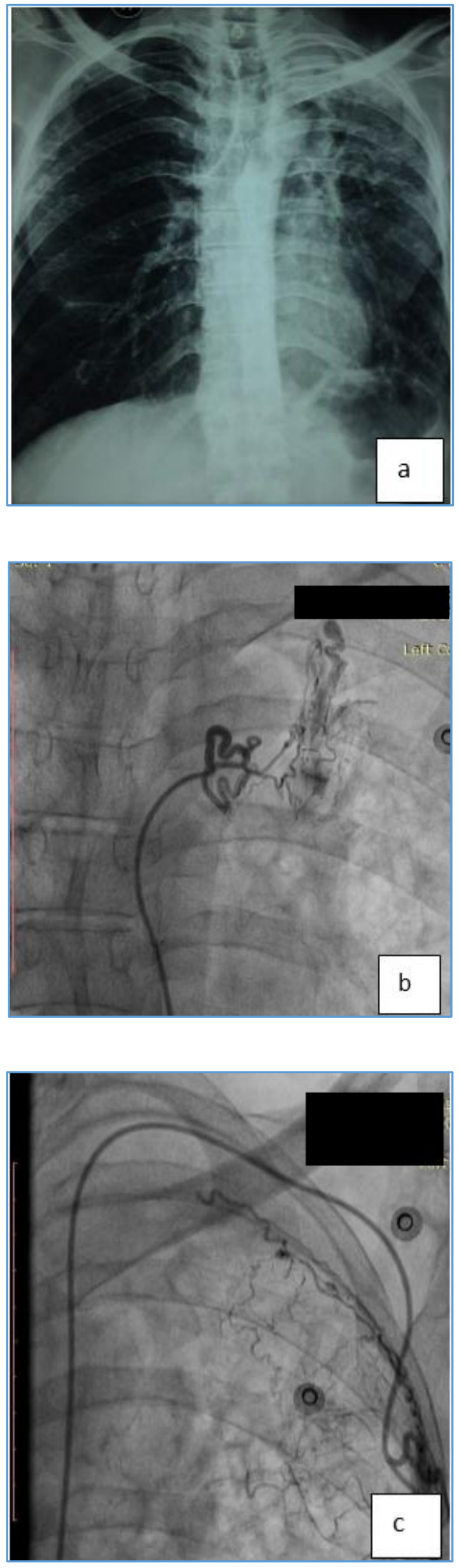

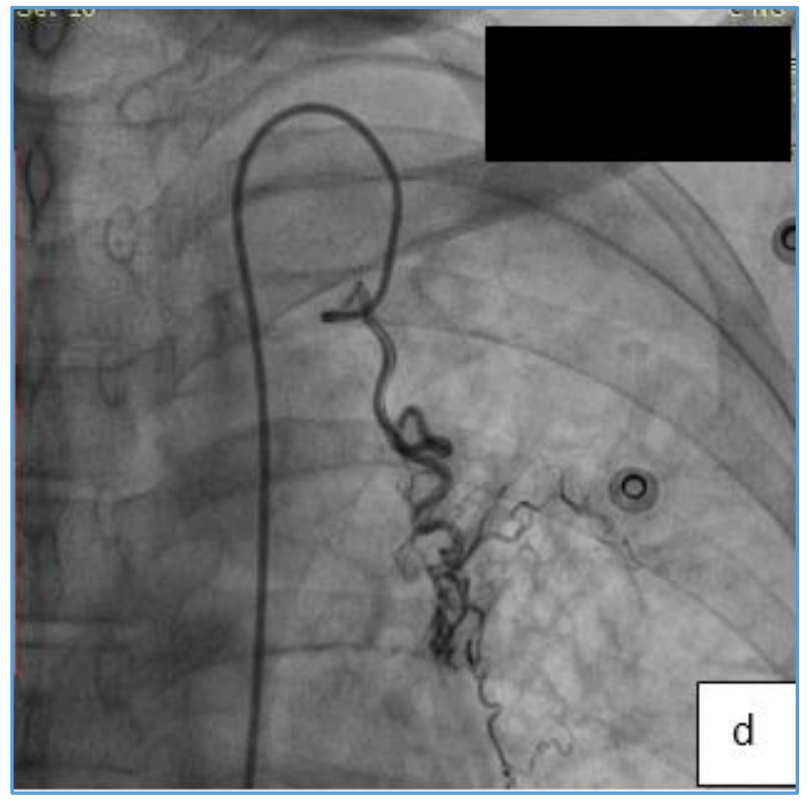

Figure 2. (a) X-ray chest shows left upper lobe collapse with pulling of trachea to ipsilateral side with raised left dome of diaphragm noted. Extensive architectural distortion with fibro-cystic changes and nodular opacities seen in left lower lobe. Few fibronodular opacities also seen in right upper zone. Figure $2(b, c, d)$ Bronchial angiogram shows hypertrophied and torturous left bronchial, lateral thoracic and internal mammary artery with arteriopulmonary shunting.

\section{DISCUSSION}

First performed in 1973 by Remy et al, BAE has become a widely accepted treatment option in the management of patients with haemoptysis. Haemoptysis occurs by similar mechanisms in benign and malignant aetiologies, that is, by local necrosis and inflammation of blood vessels. ${ }^{5,6}$ It is a well-accepted and widely used procedure in those patients who have massive haemoptysis, but unfit for lung resection due to poor lung function, bilateral pulmonary disease or medical comorbidities. It is also indicated in patients with chronic recurrent haemoptysis, mild haemoptysis with poor pulmonary reserve (FEV1<35\%) and as a bridge for immediate control until definitive measures are undertaken..$^{7-10}$ During the present analysis, acute infective pathology $(12 / 35,34.2 \% \%)$ was the commonest cause for haemoptysis followed by active tuberculosis $(11 / 35,31.4 . \%)$, tuberculosis sequelae $(10 / 35,28.5 \%)$, pulmonary aspergilloma $(2 / 35,5.7 \%)$ and consolidation was noted in majority in 20 (57.1\%) of the patients. Immediate control of haemoptysis was seen in 32 (92.4\%). On followup, recurrent haemoptysis was seen in $6 / 30$ patients with major cause of recurrence being fibrocystic changes in $3 / 6$ or consolidation in 2 and combination of above in 1 patient.

Post-TB sequelae (except aspergilloma) was the leading cause of haemoptysis in our study detected in 10/35 patients, active tuberculosis was diagnosed in $11 / 35$ patients and the diagnosis of aspergilloma was seen in $02 / 35$ patients. Prasad et al in their study observed tuberculosis as the leading cause of haemoptysis seen in $79.2 \%$ of patients and the majority of patients had moderate haemoptysis. ${ }^{11}$ Nawalet al also 
reported inactive tuberculosis as the most frequent underlying diagnosis of haemoptysis. ${ }^{12}$

Therefore, our study is consistent with the studies from developing countries, particularly India. The leading cause of haemoptysis still remains the tuberculosis and its sequelae.

During the present analysis, common complications included chest pain $(7 / 10)$, transient dissection (bronchial and intercostals) $(2 / 10)$, bronchial tree embolisation $(1 / 10)$ and monoparesis $(1 / 10)$. Anuradha et al evaluated the results of BAE in 58 patients with post-TB sequelae and documented the following post-procedure complications: chest pain in 20 (34.5\%), dysphagia in $3(5 \%)$, transient dissection of bronchial and intercostal arteries in 2 (3.4\%) patients. ${ }^{13,14}$

Thus, chest pain remains the most common postembolisation complication in the present as well as aforementioned study.

In our study during the followup up to 3 months, one patient had re-bleeding within 30 days of post-embolisation, the underlying aetiology was post-TB sequelae; however, $6 / 30$ re-bleeding $>30$ days: post-TB sequelae in 5 patients, and aspergilloma in one patient each. Similarly, a study by Racil et al reported the short ( $<30$ days) and medium-term ( $>30$ days and $<3$ years) recurrence rate of haemoptysis was $17.39 \%$ and $8.69 \%$ respectively after BAE in 53 consecutive patients. ${ }^{15}$ The $50 \%$ episodes of short-term recurrences were related to aspergilloma and $80 \%$ of the patients with aspergilloma had short-term recurrence. The long-term recurrence ( $>3$ years) of haemoptysis was also related to aspergilloma. Singhal et al also reported aspergilloma as the cause of recurrence of haemoptysis in one patient during their one-year followup. Thus, aspergilloma remains the commonest cause of recurrence of haemoptysis after embolisation and requires repeated embolisation or definitive surgical management. ${ }^{16}$

Bronchial artery embolisation has been effective and clinically useful in the management of haemoptysis in patients within malignancy and cystic fibrosis (CF). In combining the series by Fellows et al and Cohen et al, 31 of 33 patients (94\%) had immediate control of bleeding. In 1998, Brinson et al reported on $13 \mathrm{CF}$ patients undergoing 28 embolisation procedures. Nine required only one embolotherapy session, whereas four required multiple (two or three) sessions to control the haemorrhage during a single hospital admission. Three of the 13 patients returned with recurrent bleeds. The early control of major and moderate bouts of haemoptysis in young patients with $\mathrm{CF}$ is particularly valuable as lung transplantation programs become more prevalent. Bronchial artery embolisation does not appear to interfere with subsequent lung transplantation.

Few rare complications include spinal cord ischaemia and transverse myelitis; however, the use of non-ionic contrast agents has significantly reduced, if not eliminated, the risks of transverse myelitis. With the current use of non-ionic contrast media, particulate embolic agents greater than 200 $\mathrm{mm}$ and modern microcatheters or microguidewires, nontarget embolisation should be quite rare. Chest pain and dysphagia commonly occur with selective (versus super selective) embolisation within the first week following the procedure. These symptoms are secondary to the interruption of the blood supply to the posterior mediastinum and mid-portion of the oesophagus. This is less common when distal super selective catheterisation is used. ${ }^{15-17}$

\section{CONCLUSION}

Major haemoptysis is a frightening and potentially fatal complication of a variety of chronic inflammatory conditions of the lung. The development of bronchial artery embolisation techniques has revolutionised the approach to these patients. Persistent haemoptysis can be successfully controlled in as many as $90 \%$ of patients. In Indian scenario, tuberculosis remains the most common cause of massive haemoptysis.

\section{REFERENCES}

[1] Najarian KE, Morris CS. Arterial embolization in the chest. J Thorac Imaging 1998;13(2):93-104.

[2] Narasimhalu N, Sarkar M, Bhardwaj R, et al. Role of bronchial artery embolisation in the management of hemoptysis. NJMR 2015;5(3):179-84.

[3] Fidan A, Ozdogan S, Oruc 0, et al. Hemoptysis: a retrospective analysis of 108 cases. Respir Med 2002;96(9):677-80.

[4] Hirshberg B, Biran I, Glazer M, et al. Hemoptysis: etiology, evaluation, and outcome in a tertiary referral hospital. Chest 1997;112(2):440-4.

[5] Re'my J, Voisin C, Dupuis C, et al. Treatment of hemoptysis by embolization of the systemic circulation. Ann Radiol 1974;17(1):5-16.

[6] Re'my J, Arnaud A, Fardou H, et al. Treatment of hemoptysis by embolization of bronchial arteries. Radiology 1977;122(1):33-7.

[7] Uflacker R, Kaemmerer A, Picon PD, et al. Bronchial artery embolization in the management of hemoptysis: technical aspects and long term results. Radiology 1985;157(3):637-44.

[8] Rabkin JE, Astafjev VI, Gothman LN, et al. Transcatheter embolization in the management of pulmonary hemorrhage. Radiology 1987;163(2):3615.

[9] Ramakantan R, Bandekar V, Gandhi MS, et al. Massive hemoptysis due to pulmonary tuberculosis control with bronchial artery embolization. Radiology 1996;200(3):691-4.

[10] Mal H, Rullon I, Mellot F, et al. Immediate and longterm results of bronchial artery embolization for lifethreatening hemoptysis. Chest 1999;115(4):9961001.

[11] Prasad R, Garg R, Singhal S, et al. Lessons from patients with hemoptysis attending a chest clinic in India. Ann Thorac Med 2009;4(1):10-2.

[12] Nawal SK, Heda MR. Hemoptysis: a prospective analysis of 110 cases. Asian journal of biomedical and pharmaceutical sciences 2013;3(21):1-3.

[13] Eric H, Kirsch CM, Kagawa FT, et al. Utility of fiberoptic bronchoscopy before bronchial artery embolization for massive hemoptysis. AM J Roentgenol 2001;177(4):861-7. 
[14] Anuradha C, Shyamkumar NK, Vinu M, et al. Outcomes of bronchial artery embolization for life-threatening hemoptysis due to tuberculosis and post-tuberculosis sequelae. Diagn Interv Radiol 2012;18(1):96-101.

[15] Racil H, Rajhi H, Naceur BR, et al. Endovascular treatment of haemoptysis: medium and long-term assessment. Diagn Interv Imaging 2013;94(1):38-44.
[16] Singhal S, Banode P. Bronchial artery embolization in patients presenting with massive hemoptysis: initial experience from a rural tertiary centre of central India. ISRN Pulmonology 2011.

[17] Burke CT, Mauro MA. Bronchial artery embolization. Seminars in Intervention Radiology 2004;21(1):43-8. 